Multidisciplinary Journal - Volume 3, Nomor 2, 2020

Contents list available at Multidisciplinary Journal website Multidisciplinary Journal

Journal homepage: https://jurnal.unej.ac.id/index.php/multijournal

\title{
Pengaruh Pengetahuan dan Sikap terhadap Perilaku Penggunaan APD pada Buruh Tani Tembakau (Studi di PTPN X Kabupaten Jember)
}

\author{
The Effect of Knowledge and Motivation Toward Behavior of Personal Protective Equipment Use in \\ the Tobacco Farm Workers in PTPN X Jember.
}

\author{
Nurina Aprilya ${ }^{1}$, F.X. Ady Soesetijo², Hadi Prayitno ${ }^{3}$ \\ ${ }^{1}$ Mahasiswa Pascasarjana Ilmu Kesehatan Masyarakat Universitas Jember ${ }^{2}$ Fakultas Kedokteran Gigi Univeristas Jember ${ }^{3}$ Fakultas \\ Ilmu Sosial dan Politik Universitas Jember \\ nurinaaprilya9@gmail.com
}

\begin{abstract}
ABSTRAK. Penggunaan APD sangatlah penting sebagai upaya untuk mencegah terjadinya kecelekaan pada petani dan penyait akibat kerja seperti green tobacco sickness (GTS) pada buruh tani tembakau Penelitian ini bertujuan mengetahui pengaruh dari pengetahuan dan sikap terhadap perilaku penggunaan alat pelindung diri. Jenis penelitian adalah observasional analitik dengan desain cross sectional Data dalam penelitian ini menggunakan data primer dari kuisioner terhadap 175 responden buruh tani. Penelitian ini menggunakan uji regresi logistik dengan alat bantu SPSS dalam menganalisis data. Hasil pengujian memperoleh nilai sig pengetahuan sebesar 0,030 yang artinya antara pengetahuan terhadap perilaku penggunaan alat pelindung diri terdapat pengaruh yang signifikan dan nilai sig sikap sebesar 0,000 membuktikan bahwa antara sikap terhadap perilaku penggunaan alat pelindung diri terdapat pengaruh yang signifikan.
\end{abstract}

Kata Kunci: pengetahuan, sikap, perilaku penggunaan APD

ABSTRACt. The utilising of Personal Protective Equipment (PPE) is necessary in order to prevent both accident and workrelated illness among farmer, such as Green Tobacco Sickness (GTS) within tobacco farmer. The aim of this study was to understand the role of knowledge and attitude toward the PPE usage behavior. This was observational analytics study with cross sectional design. The participant of this study was 175 farmers. In addition, statistical analysis was performed by logistic regression through SPSS. This study found that the significant level of knowledge and attitude toward PPE usage behavior is 0.030 and 0.000 , respectively. It indicated that there is correlation between both knowledge and attitude toward PPE usage behavior among farmer.

Keyword: Knowledge, Attitude, PPE utilising behavior

\section{Pendahuluan}

Indonesia merupakan negara yang memiliki berbagai jenis tanaman, salah satunya adalah tembakau. Tembakau merupakan primadona di Indonesia karena merupakan bahan utama dari perusahaan rokok di Indonesia. Jember merupakan kota penghasil tembaaku tertinggi di Jawa Tiimur dengan jumlah produksi mencapai 31. 284 ton tembakau pada tahun 2012 (BPS, 2015). Tanaman tembakau mengandung nikotin, yang merupakan salah satu zat kimia berbahaya. Nikotin pada tembakau dapat masuk ke dalam tubuh manusia dan menimbulkan penyakit yang di sebut dengan Green Tobacco Sickness (GTS) (Curwin, et al, 2005).

Green Tobacco Sickness (GTS) merupakan penyakit yang disebabkan oleh penyerapan nikotin melalui kulit pada buruh tani yang tidak menggunakan alat pelindung diri. Risiko keracunan nikotin terjadi ketika tembakau dipanen dalam keadaan basah karena hujan, embun maupun keringat dari buruh tani, sehingga dapat terserap melalui kulit dan masuk ke dalam aliran darah (Osha- 
Niosh, 2015).

Beberapa penelitian terkait dengan bahaya tembakau telah dilakukan, salah satunya yang dilakukan oleh Rokhma, et al (2014) menunjukkan sebagian besar petani tembakau memiliki pengetahuan yang rendah tentang GTS yaitu sebesar 96,6\%, serta memiliki tindakan pencegahan GTS yang kurang baik (86,5\%).

Penggunaan APD sangatlah penting sebagai upaya untuk mencegah terjadinya GTS pada buruh tani tembakau. Alat pelindung diri harus memiliki persyaratan yang sesuai dengan tempat kerja, diantaranya fleksibel dan tidak menimbulkan bahaya (Suma'mur, 2014). Alat pelindung diri pada buruh tani antara lain masker, baju lengan panjang, celana panjang, sepatu, sarung tangan dan juga topi (Wismaningsih dan Oktaviasari, 2015).

Penelitian yang dilakukan oleh Winandar (2016) menyebutkan faktor-faktor yang selalu mempengaruhi dari penggunaan APD pada buruh tani yaitu pengetahuan dan sikap. Berdasarkan latar belakang diatas, masalah yang dapat dirumuskan adalah apakah ada pengaruh antara pengetahuan dan sikap terhadap perilaku penggunaan alat pelindung diri pada buruh tani tembakau di Kabupaten Jember.

\section{Metode Penelitian}

Penelitian ini merupakan penelitian kuantitatif dengan jenis penelitian yang digunakan adalah survey analitik yang bertujuan untuk menganalisis pengaruh pengetahuan dan sikap terhadap perilaku penggunaan APD pada buruh tani tembakau.

Lokasi penelitian ini di kecamatan Ajung, Kabupaten Jember. Populasi dalam penelitian ini adalah buruh tani tembakau dengan jumlah sampel sebanyak 175 responden.

Penelitian ini menggunakan data primer yang berasal dari responden yang mengisi kuisioner yang dibagikan oleh peneliti.

Masing-masing kuisioner variabel terdiri dari 9 item untuk pengetahuan, 9 item untuk sikap, dan untuk perilaku menggunakan lembar observasi. Analisis yang digunakan adalah regresi logistik menggunakan alat SPSS 22.0

3. Hasil dan Pembahasan

1. Analisis Univariat

a. Tingkat Pengetahuan

Tabel 1. Analisis Univariat Pengetahuan

\begin{tabular}{clcc}
\hline Variabel & Kategori & N & \% \\
\hline \multirow{4}{*}{ Pengetahuan } & Baik & 0 & 0 \\
& Cukup & 77 & 44 \\
& Kurang & 87 & 56 \\
& Total & 175 & 100 \\
\hline
\end{tabular}

Tabel 1 menjelaskan distribusi dari pengetahuan dimana kategori pengetahuan baik sebanyak $0 \%$, kategori pengetahuan cukup $44 \%$ dan kategori pengetahuan kurang adalah $56 \%$ atau 87 responden.

b. Sikap

Tabel 2. Analisis Univariat Sikap

\begin{tabular}{clcc}
\hline Variabel & Kategori & $\mathbf{N}$ & $\mathbf{\%}$ \\
\hline \multirow{3}{*}{ Sikap } & Baik & 73 & 41,7 \\
& Kurang & 103 & 58,3 \\
& Total & 175 & 100 \\
\hline
\end{tabular}

Tabel 2 menjelaskan distribusi dari sikap dimana kategori sikap baik sebanyak $41,7 \%$ atau sebanyak 73 responden. Sedangkan sikap kurang sebanyak $58,3 \%$ atau 102 responden.

c. Perilaku

Tabel 3. Analisis Univariat Perilaku

\begin{tabular}{clcc}
\hline Variabel & Kategori & $\mathbf{N}$ & \% \\
\hline \multirow{3}{*}{ Perilaku } & Baik & 66 & 37,7 \\
& Kurang & 109 & 62,3 \\
& Total & 175 & 100 \\
\hline
\end{tabular}

Tabel 3 menunjukkan bahwa dari jumlah total responden 175 orang, sebanyak 66 responden (38\%) memiliki perilaku yang baik terkait dengan penggunaan alat pelindung diri, sedangkan sisanya 109 responden (62\%) memiliki perilaku yang kurang baik terkait penggunaan alat pelindung diri pada saat bekerja

2. Analisis Bivariat

Tabel 4. Analisis bivariat

\begin{tabular}{lrrr}
\hline \multicolumn{1}{c}{ Variabel } & B & S.E & Sig \\
\hline Pengetahuan & 1,165 &, 536 & 0,030 \\
Sikap & 4,399 &, 565 & 0,000 \\
\hline
\end{tabular}

Tabel hasil uji regresi logistik didapatkan nilai koefien Beta pada variabel pengetahuan sebesar 1,165 dan variabel sikap sebasar 4,399. Adapun nilai SE pada variabel pengetahuan didapatkan nilai 0,536 dan variabel sikap 0,565. Nilai sig dari variabel pengetahuan 0,030 dan nilai sig dari variabel sikap 0,000 .

Pengetahuan dari hasil penelitian menunjukkan nilai sig lebih kecil daripada nilai sig $(0,05)$ yaitu 0,030 . Pengetahuan menurut Notoatmodjo (2014) merupakan tindakan atau perilaku menusia yang terjadi setelah penginderaan dari objek tertentu, termasuk dalam perilaku penggunaan alat pelindung diri (APD $)^{[8]}$ Seperti yang disampaikan oleh Dzulfiqar dan Handayani (2016), pengetahuan berkaitan dengan perilaku yang akan ditimbulkan ${ }^{[9]}$. Buruh tani tidak tahu sama sekali tentang GTS, risiko yang dapat terjadi apabila mereka bekerja 
dengan tembakau namun tidak menggunakan APD lengkap sebagai upaya mencegah terjadinya gejala GTS. Rata-rata buruh tani hanya mengetahui tentang praktek di lapangan mulai dari proses pembibitan tembakau hingga panen.

Hal tersebut dikarenakan kurangnya penyuluhan dari perusahaan, sehingga pengetahuan mereka juga kurang terkait dengan bahaya tembakau, terkait dengan pentingnya penggunaan alat pelindung diri secara lengkap saat bekerja. Penelitian ini sejalan dengan penelitian Darmayanti (2015), bahwa terdapat hubungan antara tingkat pengetahuan petani dengan perilaku penggunaan APD dengan nilai signifikansi $<0,05$ ( $p$-value $=0,000)^{[10]}$.

Terkait dengan sikap terdapat pengaruh terhadap perilaku penggunaan alat pelindung diri dengan nilai sig hitung kurang dari nilai sig $(0,05)$ yaitu 0,000 . Semakin baik sikap buruh tani maka motivasi untuk berperilaku menggunakan APD akan semakin baik pula. Hasil penelitian ini sejalan dengan salah satu teori Allport (dalam Azwar, 2011) yang mendefinisikan sikap sebagai kesiapan individu untuk bereaksi terhadap suatu objek dengan cara-cara tertentu. ${ }^{[1]}$

Buruh tani yang termotivasi untuk menjaga kesehatan dan keselamatan diri akan memiliki sikap yang baik, salah satunya yaitu menggunakan APD pada saat bekerja, mematuhi peraturan untuk menggunakan APD. Sebaliknya buruh tani dengan sikap yang kurang baik cenderung kurang memperhatikan kesehatan dan keselamatan kerja, terlihat dari sikap mereka acuh terhadap penggunaan alat pelindung diri.

Kesimpulan dari penelitian ini sebagian buruh tani memiliki sikap kurang baik terkait dengan penggunaan APD. Buruh tani kurang menganggap penting dan bukanlah suatu keharusan menggunakan APD pada saat bekerja, hal ini dikarenakan faktor kenyamanan. Beberapa buruh tani tidak menggunakan sarung tangan pada saat memetik tembakau, alasannya kurang nyaman. Ada juga yang tidak menggunakan sepatu boot tapi diganti dengan sandal dan memakai kaos kaki.

Penelitian Liswanti (2017) sejalan dengan penelitian ini, menyebutkan ada hubungan antara sikap dengan perilaku penggunaan APD $(p=0,004, \alpha=0,05)^{[12]}$. Sejalan juga dengan penelitian Gunawan dan Mudayana (2016) menyatakan adanya pengaruh sikap terhadap perilaku penggunaan APD dengan nilai $p$-value $0,031<0,05 \cdot{ }^{[13]}$

\section{Kesimpulan}

Kesimpulan dari penelitian ini diantaranya:

1. Sebanyak 66 buruh tani (38\%) memiliki perilaku yang baik terkait dengan penggunaan alat pelindung diri.

2. Ada pengaruh pengetahuan terhadap perilaku penggunaan alat pelindung diri pada buruh tani tembakau.

3. Ada pengaruh sikap terhadap perilaku penggunaan alat pelindung diri.

\section{Ucapan Terima Kasih}

Terima kasih kepada PTPN X Jember yang telah berkenan memberikan ijin atas pelaksanaan penelitian ini.

\section{Referensi}

Badan Pusat Statistik. 2015. Statisitik Upah Buruh Tani Badan Pusat Statistik. Jakarta

Curwin B.D, Hein. M.J, Sanderson W.T, Nishioka M.G Buhler W. 2005. Nicotine Exposure and Decontamination On Tobacco Harvesters Hand. Journal Of Occupational Hygiene. 49(5): 407-413

OSHA-NIOSH. 2015. Recommended Practice of Green Tobacco Sickness. DHHS (NIOSH) Pubclication Number 2015-104 OSHA3765-2015.

Rokhma, et al. 2014. Analisis Faktor Risiko Green Tobacco Sickness (GTS) dan Metode Penannganannya pada Petani Tembakau. Penelitian Hibah Dosen Muda. Universitas Jember.

Suma'mur. 2014. Kesehatan Kerja dalam Prespektif Hiperkes \& Keselamatan Kerja. Jakarta: Justisia Teknika

Wismaningsih E, Oktaviasari, D. 2015. Faktor yang Berhubungan dengan Penggunaan Alat Pelindung Diri (APD) pada Petani Penyemprot di Kecamatan Ngantru Kabupaten Tulungagung. Jurnal Wiyata. 2 (2): 102-107.

Winandar A. 2016. Faktor-Faktor yang Berhubungan dengan Penggunaan Alat Pelindung Diri (APD) pada Petani yang Menggunakan Pestisida Gampong di Kecamatan Blang Pidie. Serambi Akademi IV (1):37-43.

Notoatmodjo. 2014. Ilmu Perilaku Kesehatan. Jakarta: Rineka Cipta.

Dzulfiqar, A., Handayani, P. 2016. Faktor-Faktor yang Berhubungan dengan Perilaku Kesehatan pada Pekerja Bengkel Las di Wilayah Pejompongan Kelurahan Bendungan Hilir Jakarta Pusat Tahun 2016. Jakarta: Jurnal Fakultas Ilmu Kesehatan Universitas Esa Unggul.

Darmayanti. 2015. Hubungan Antara Tingkat Pengetahuan demgan Kepatuhan dalam Menggunakan Alat Pelindung Diri pada Petani Pengguna Pestisida. [Skripsi Ilmiah] Bali: Program Studi Ilmu Keperawatan Fakultas Kedokteran Universitas Udayana.

Azwar, S. 2011. Sikap Manusia: Teori dan Pengukurannya. Jakarta: Pustaka Pelajar.

Lismawati, Y. 2017. Hubungan Tingkat Pengetahuan dan Sikap dengan Perilaku Penggunaan Alat Pelindung Diri pada Mahasiswa Prodi DIII Analis Kesehatan STIKes BTH Tasikmalaya. Jurnal Kesehatan Bakti Tunas Husada Volume 17 Nomor 2 Agustus 2017

Gunawan, I., Mudayana, Ahmad A. Hubungan Antara Pengetahuan, Sikap dan Motivasi dengan Perilaku Penggunaan Alat Pelindung Diri pada Pekerja Bagian Produksi PT. Katingan Indah Utama, Kabupaten Kotawaringin Timur, Provinsi Kalimantan Tengah. Unnes Journal of Public Health. 